УДК 336.63

$10.17213 / 2075-2067-2021-1-231-237$

\title{
ПРАКТИЧЕСКАЯ АПРОБАЦИЯ МЕТОДИКИ АНАЛИЗА ЭФФЕКТИВНОСТИ ИСПОЛЬЗОВАНИЯ ТРУДОВЫХ РЕСУРСОВ ОРГАНИЗАЦИИ
}

\author{
(C) 2021 г. Н. А. Федоренко, И. Б. Рудская
}

\author{
Азово-Черноморский инженерный институт, \\ Донской государственный аграрный университет, г. Зерноград, Россия
}

Целью исследования является апробация методики анализа эффективности использования трудовых ресурсов и разработка мероприятий, направленных на повышение производительности труда и рентабельности персонала ОАО «Сахарный завод «Ленинградский».

Методологическую базу исследования представляют монографический, сравнительный, графический, факторный анализ и другие методы экономических исследований. Применение этих методов позволит установить динамику эффеективности использования трудовых ресурсов на базе пилотной организачии, выявить причины происходящих изменений и разработать направления повышения производительности труда и рентабельности персонала.

Результаты исследования. На основе проведенного анализа была выявлена недостаточная эффективность использования трудовых ресурсов в ОАО «Сахарный завод «Ленинградский» и необходимость в иелях ее повышения разработки направлений увеличения прибыли от продаж, уровня товарности и производительности труда работников исследуемой организациии.

В результате исследования были разработаны резервы роста интенсивности и эффективности использования трудовых ресурсов в ОАО «Сахарный завод «Ленинградский» на основе модернизации, дальнейшей автоматизации производства, роста объемов реализации продукичии.

Перспективу исследования составляет практическая реализация предложенных направлений и фиксачия последующей динамики производительности труда и рентабельности персонала в рассматриваемой организации, а также проведение исследования эффективности использования трудовых ресурсов в других сельскохозяйственных организациях с иелью разработки мероприятий по ее повымению.

Ключевые слова: анализ; трудовые ресурсы; производительность труда; рентабельность персонала.

\section{PRACTICAL TESTING OF THE EFFECTIVENESS ANALYSIS METHODOLOGY USE OF THE ORGANIZATION'S LABOR RESOURCES}

\author{
(C) $2021 \quad$ N. A. Fedorenko, I. B. Rudskaya
}

Azov-Black Sea Engineering Institute, Don State Agrarian University, Zernograd, Russia

The purpose of the study is to test the methodology for analyzing the efficiency of the use of labor resources and the development of measures aimed at increasing labor productivity and profitability of the personnel of JSC Sugar Plant Leningradsky. 
The methodological basis of the study is represented by monographic, comparative, graphical, factor analysis and other methods of economic research. The application of these methods will make it possible to establish the dynamics of the efficiency of the use of labor resources on the basis of a pilot organization, to identify the reasons for the changes taking place and to develop directions for increasing labor productivity and personnel profitability.

Research results. On the basis of the analysis, insufficient efficiency of the use of labor resources at OJSC Sugar Plant Leningradsky was revealed and the need, in order to increase it, to develop directions for increasing profit from sales, the level of marketability and labor productivity of employees of the studied organization. As a result of the study, reserves were developed for increasing the intensity and efficiency of the use of labor resources at the Leningradsky Sugar Plant OJSC on the basis of modernization, further automation of production, and an increase in product sales.

The prospect of the study is the practical implementation of the proposed directions and fixing the subsequent dynamics of labor productivity and profitability of personnel in the organization under consideration, as well as conducting a study of the efficiency of using labor resources in other agricultural organizations in order to develop measures to improve it.

Key words: analysis; labor resources; labor productivity; personnel profitability.

Введение. Обеспеченность необходимыми трудовыми ресурсами в достаточной степени, их рациональное использование, а также высокий уровень производительности труда является важным фактором для роста объемов продукции и эффективности производства предприятия. Поэтому решающим фактором обеспечения устойчивого экономического роста предприятия является развитие и повышение эффективности использования его трудовых ресурсов.

Анализ эффективности использования трудовых ресурсов в ОАО «Сахарный завод «Ленинградский». Достижение какого-либо результата в процессе производства может быть получено с различной степенью эффективности труда. Меру эффективности труда персонала называют производительностью труда, которая представляет собой результативность труда или способность работника производить за единицу рабочего времени определенный объем продукции [3].

Под производительностью труда понимают количество продукции, которую производит работник в единицу времени (выработка), или количество времени, использованного на производство единицы продукции (трудоемкость) [2].

Оценивать производительность труда необходимо, так как она является одним из важ- ных качественных показателей работы предприятия, ее рост выступает главным фактором увеличения эффективности производства, роста объемов выпускаемой продукции и сокращения ее себестоимости, повышения эффективности деятельности предприятия.

Расчет показателей производительности труда работников предприятия проводится с целью определения причин произошедших изменений и поиска резервов увеличения годовой выработки.

Объектом исследования является предприятие пищевой промышленности ОАО «Сахарный завод «Ленинградский» Ленинградского района Краснодарского края.

Данные для расчета динамики и анализа производительности труда персонала анализируемого хозяйства сведены в таблицу 1.

Из таблицы 1 следует, что в рассматриваемом предприятии в 2019 г. наблюдался рост производительности труда как всех работников предприятия (на $36,6 \%$ ), так и работников сахарного производства (на 35,3\%). Однако в 2018 г. производительность труда работников ОАО «Сахарный завод «Ленинградский» сократилась на 20,8\% по сравнению с 2017 г., аналогичную динамику имеет и производительность труда работников, занятых в производстве сахара, мелассы и жома, которая сократилась на $21,3 \%$. 
Желательно, чтобы темпы роста производительности труда опережали темпы роста его оплаты, так как более быстрый рост производительности труда по сравнению с ростом средней заработной платы работников представляет одно из важнейших условий уменьшения затрат по заработной плате на производство продукции, снижения ее себестоимости и увеличения прибыли [1]. Поэтому целесообразно проанализировать соотношение темпов роста производительности труда и его оплаты в ОАО «Сахарный завод «Ленинградский» за весь изучаемый период (рис. 1).

Из рисунка 1 видно, что в 2017-2018 гг. темпы роста затрат на заработную плату работников основного производства в ОАО «Сахарный завод «Ленинградский» превышали темпы роста их производительности труда. Наибольшее превышение указанных темпов было достигнуто в 2018 г., в котором коэффициент опережения составил 1,428. Данный факт свидетельствует о недостаточно рациональной организации оплаты труда и о наличии возможности улучшения мотивации работников увеличивать производительность труда.

В 2019 г. в рассматриваемом предприятии индекс производительности туда работников основного производства превысил индекс их средней заработной платы, вследствие чего коэффициент опережения составил 1,202.

Обобщающим показателем эффективности использования трудовых ресурсов предприятия является рентабельность персонала, представляющая собой соотношение прибыли от продаж и среднесписочной численности работников предприятия [4].

Динамику рентабельности персонала, занятого в основной отрасли рассматриваемого предприятия, за анализируемый период представим в виде гистограммы (рис. 2).

Из рисунка 2 следует, что в 2019 г. прибыль от продаж основной продукции, приходящаяся на одного работника сахарного производства, возросла на 23,9\% по сравнению с 2017 г., но сократилась на 18,0\% относительно уровня 2018 г.

В целях определения резервов повышения эффективности использования трудовых ресурсов исследуемой организации целесообразно провести факторный анализ изменения рентабельности персонала в отчетном году по сравнению с базисным годом.

Проведем анализ эффективности использования трудовых ресурсов, применив трехфакторную мультипликативную модель [2].

Таблица 1

Анализ производительности труда в ОАО «Сахарный завод «Ленинградский» в 2017-2019 гг.

\begin{tabular}{|c|c|c|c|c|c|}
\hline \multirow{2}{*}{ Показатели } & \multicolumn{3}{|c|}{ Годы } & \multicolumn{2}{|c|}{$\begin{array}{l}\text { Цепной темп } \\
\text { роста, \% }\end{array}$} \\
\hline & 2017 & 2018 & 2019 & $\begin{array}{c}2018 \text { г. } \\
\text { К } 2017 \text { г. }\end{array}$ & $\begin{array}{r}2019 \text { г. } \\
\text { К } 2018 \text { г. }\end{array}$ \\
\hline $\begin{array}{l}\text { Среднегодовая численность работников } \\
\text { предприятия, чел. }\end{array}$ & 697 & 671 & 668 & 96,3 & 99,6 \\
\hline $\begin{array}{l}\text { в том числе: } \\
\text { — занятых в основном производстве }\end{array}$ & 567 & 553 & 554 & 97,5 & 100,2 \\
\hline $\begin{array}{l}\text { Произведено валовой продукции } \\
\text { — всего, тыс. руб. }\end{array}$ & 5029154 & 3835063 & 5213699 & 76,3 & 135,9 \\
\hline $\begin{array}{l}\text { в том числе: } \\
\text { - продукции основного производства }\end{array}$ & 4895633 & 3760097 & 5097955 & 76,8 & 135,6 \\
\hline $\begin{array}{l}\text { Производительность труда работников } \\
\text { по предприятию в целом, тыс. руб./чел. }\end{array}$ & 7215 & 5715 & 7805 & 79,2 & 136,6 \\
\hline $\begin{array}{l}\text { в том числе работников: } \\
\text { — занятых в основном производстве }\end{array}$ & 8634 & 6799 & 9202 & 78,7 & 135,3 \\
\hline
\end{tabular}




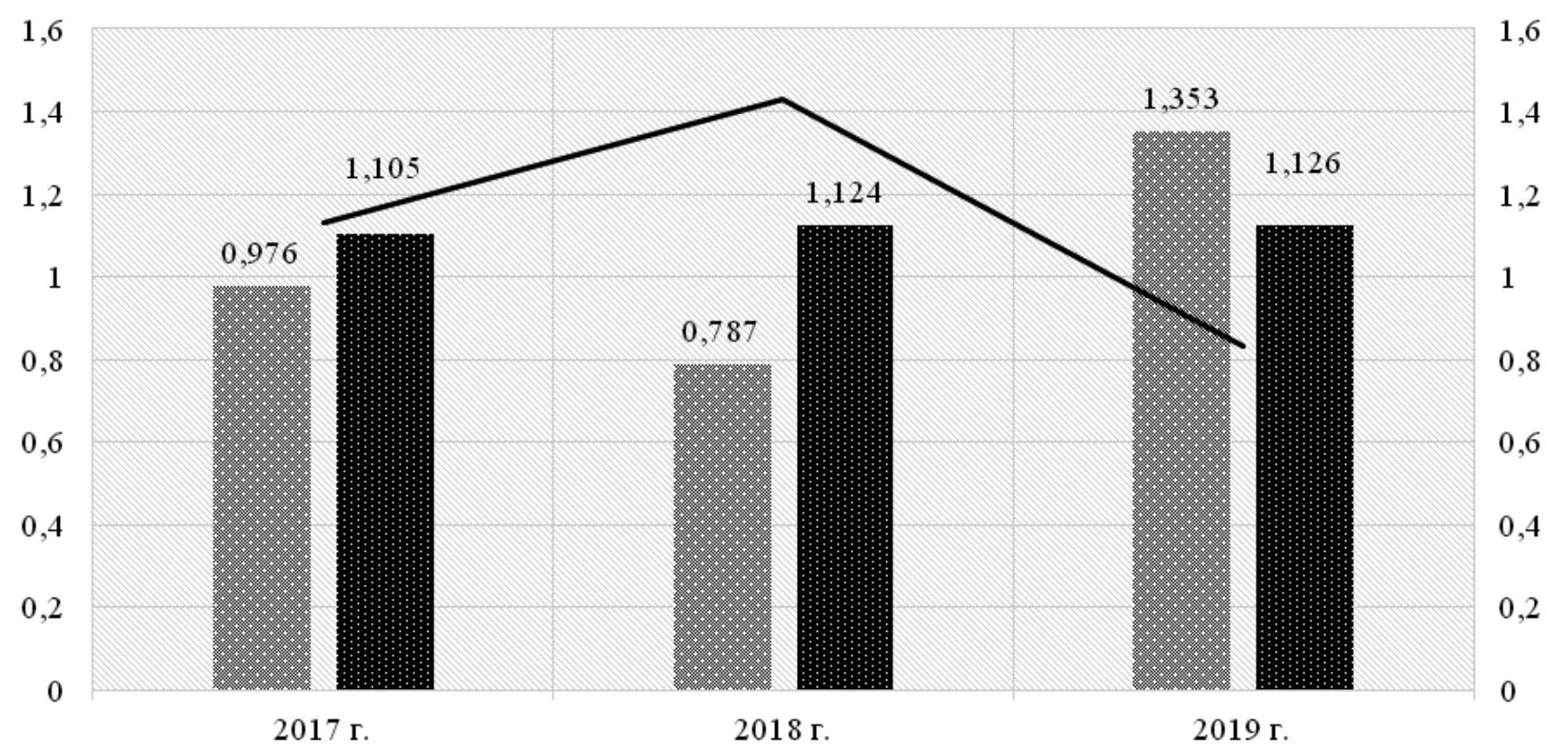

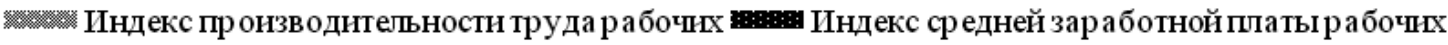

— Коэффищиент затрат на заработную плату

Рис. 1. Сравнение индексов производительности труда и заработной платы работников, занятых в основном производстве в 2017-2019 гг.

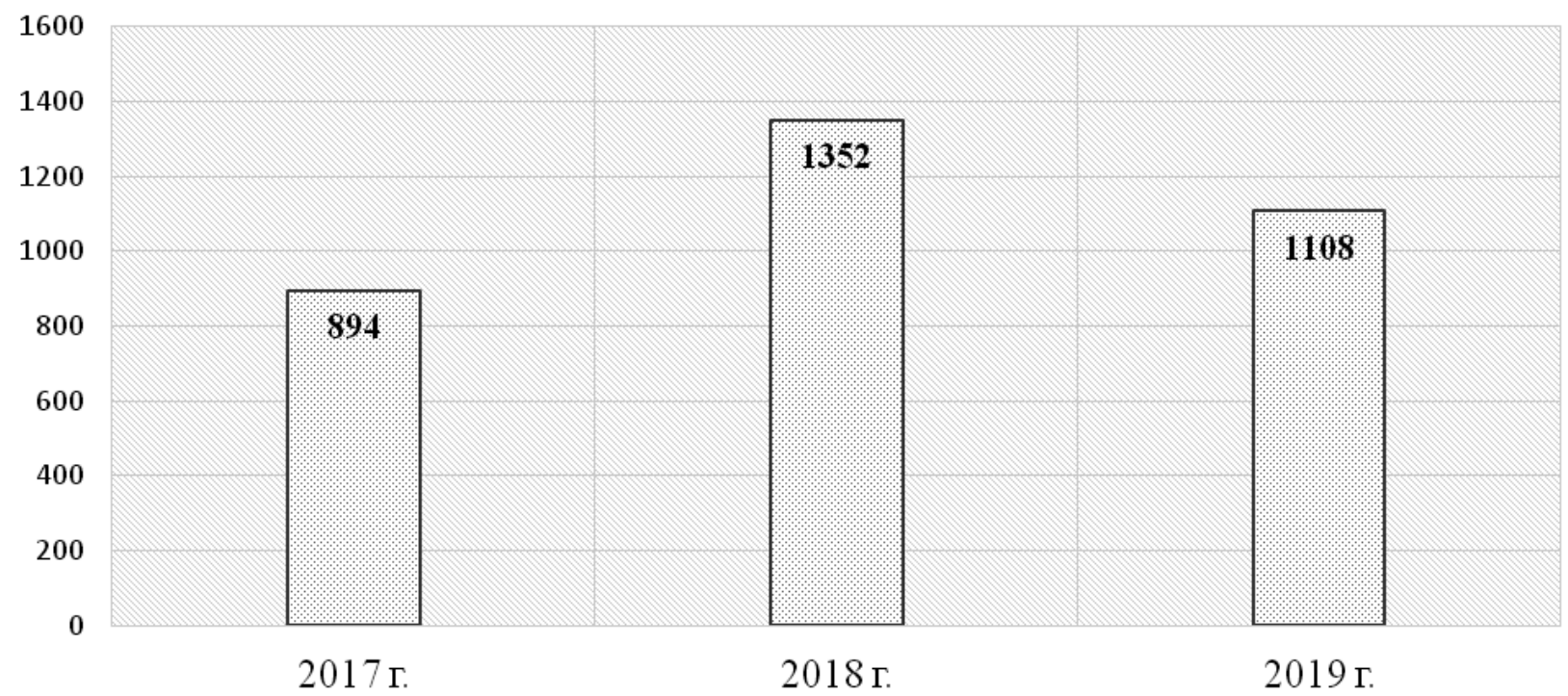

图 Прибыль на одного работника, занятого в основномпроизводстве, тыс. руб./чел.

Рис. 2. Рентабельность персонала в ОАО «Сахарный завод «Ленинградский» за период 2017-2019 гг. 


\section{Факторный анализ рентабельности персонала} в ОАО «Сахарный завод «Ленинградский»

\begin{tabular}{|c|c|c|}
\hline Показатели & Алгоритм расчета & Значение \\
\hline \multicolumn{3}{|l|}{ Прибыль на одного работника: } \\
\hline — в 2018 году, тыс. руб. & $\mathrm{P}_{0}=\mathrm{R}_{\text {пр } 0} \times \mathrm{YT}_{0} \times \Gamma \mathrm{B}_{0}$ & 1352 \\
\hline — в 2019 году, тыс. руб. & $\mathrm{P}_{1}=\mathrm{R}_{\text {пр } 1} \times \mathrm{YT}_{1} \times \Gamma \mathrm{B}_{1}$ & 1108 \\
\hline $\begin{array}{l}\text { Отклонение рентабельности персонала, } \\
\text { тыс. руб. }\end{array}$ & $\Delta \mathrm{P}=\mathrm{P}_{1}-\mathrm{P}_{0}$ & -244 \\
\hline \multicolumn{3}{|l|}{ в том числе за счет изменения: } \\
\hline — рентабельности продаж & $\Delta \mathrm{P}_{\text {rпр }}=\left(\mathrm{R}_{\text {пр1 }}-\mathrm{R}_{\text {пр0 }}\right) \times \mathrm{YT}_{0} \times \Gamma \mathrm{B}_{0}$ & -486 \\
\hline - уровня товарности & $\Delta \mathrm{P}_{\mathrm{yт}}=\mathrm{R}_{\text {пр1 }} \times\left(\mathrm{YT}_{1}-\mathrm{YT}_{0}\right) \times \Gamma \mathrm{B}_{0}$ & -48 \\
\hline — годовой выработки работника & $\Delta \mathrm{P}_{\text {гв }}=\mathrm{R}_{\text {пр1 }} \times \mathrm{YT}_{1} \times\left(\Gamma \mathrm{B}_{1}-\Gamma \mathrm{B}_{0}\right)$ & 290 \\
\hline
\end{tabular}

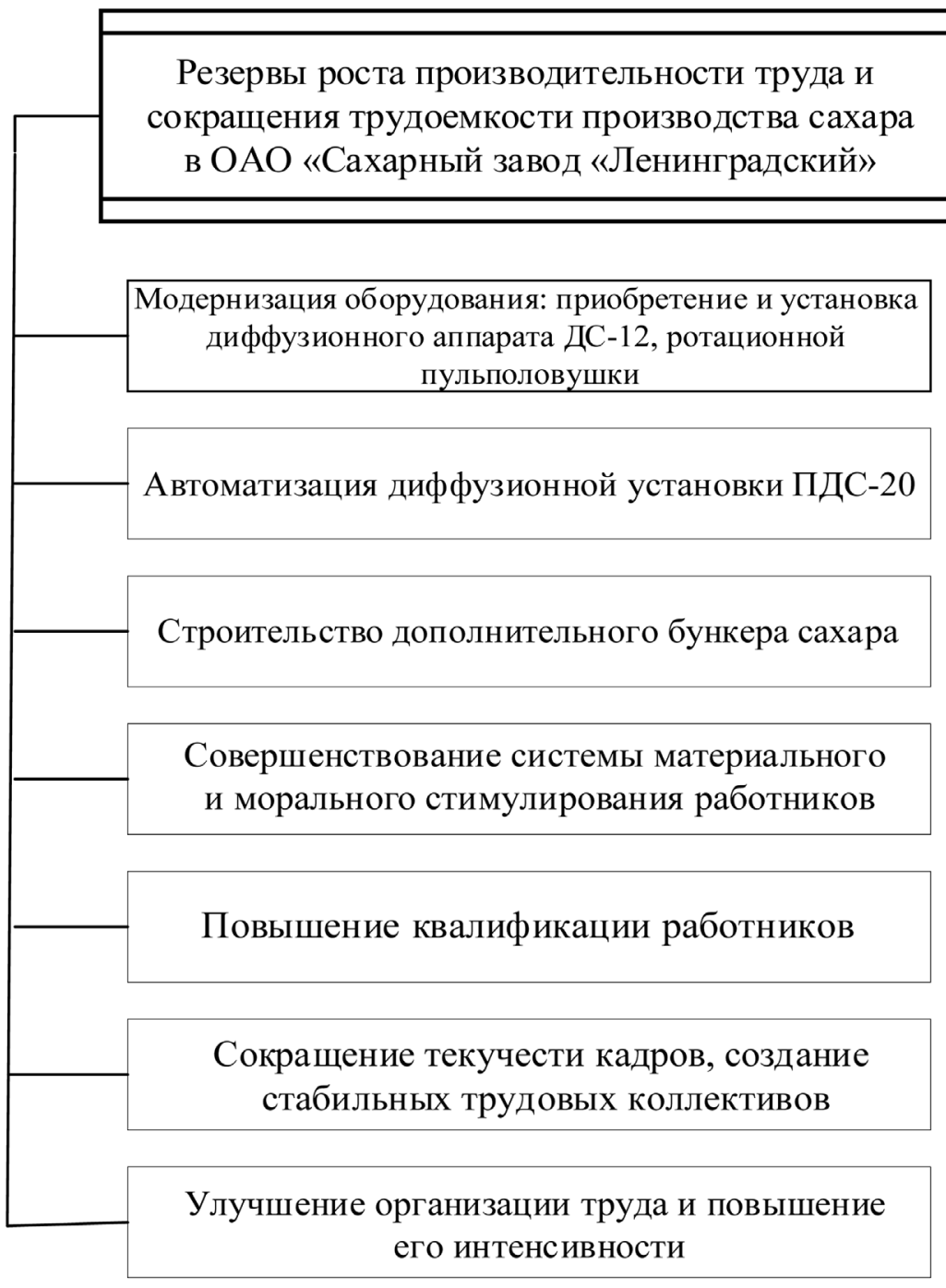

Рис. 3. Резервы роста интенсивности и эффективности использования трудовых ресурсов в исследуемой организации 
Методика анализа и определение влияния факторов на изменение прибыли от продаж в расчете на одного работника, представлены в таблице 2 .

На основе проведенного факторного анализа рентабельности персонала, представленного в таблице 2 , было выяснено, что основной причиной сокращения прибыли, приходящейся на одного работника основного производства, в 2019 г. по сравнению с 2018 г. является уменьшение рентабельности продаж на 5,7 п.п., сократившее рентабельность персонала на 486 тыс. руб./чел. Уменьшение уровня товарности на 6,9 п.п. также привело к сокращению рентабельности персонала на 48 тыс. руб./чел. Увеличение годовой выработки работника основного производства на 2402,64 тыс. руб., напротив, способствовало повышению прибыли, заработанной работником сахарного производства в отчетном году на 290 тыс. руб. по сравнению с базисным.

Приведенные результаты анализа свидетельствуют о недостаточной эффективности использования трудовых ресурсов в ОАО «Сахарный завод «Ленинградский» и о необходимости в целях ее повышения заняться вопросами увеличения прибыли от продаж, уровня товарности и дальнейшего роста производительности труда. В целях повышения производительности труда, сокращения трудоемкости производства сахара, роста прибыли от продаж сахара и в конечном итоге рентабельности персонала и в целом эффективности деятельности ОАО «Сахарный завод «Ленинградский» нами была разработана система мер, схематически представленная на рисунке 3.

Из рисунка 3 видно, что в рассматриваемой организации увеличение производительности труда работников на основе модернизации, дальнейшей автоматизации производства, роста объемов реализованной продукции позволит увеличить эффективность использования трудовых ресурсов.

Заключение. Подводя итог проведенного исследования, можно заключить, что во всей совокупности ресурсов предприятия трудовые ресурсы занимают особое место. От качества и эффективности их использования во многом зависят повышение уровня производства продукции, устойчивый эко- номический рост предприятия и его конкурентоспособность. В ОАО «Сахарный завод «Ленинградский» была установлена недостаточная эффективность использования трудовых ресурсов, для повышения которой нами были предложены рекомендации, базирующиеся на модернизации, дальнейшей автоматизации производства, росте объемов реализации продукции.

\section{Литература}

1. Рудская И. Б., Федоренко Н.А. Анализ эффективности использования кадрового потенциала аграрного предприятия // Современные научные исследования: проблемы и перспективы: Материалы IV Международной научно-практической конференции (14-15 ноября 2019 г., г. Зерноград) / под общ. ред. М.Н. Крыловой. - Москва: Перо, 2019. - C. 108-113.

2. Савищкая Г.В. Экономический анализ: учебник. 14-е изд., перераб. и доп. - М.: ИНФРА-М, 2017. - 649 c.

3. Семкин А.Г. Механизм развития кадрового потенциала в системе АПК // Экономика сельского хозяйства России. - 2017. №4. - C. 51-54.

4. Шарипов С., Харисов Г. Оценка эффективности использования производственных ресурсов АПК // АПК: экономика, управление. - 2017. - №3. - С. 52-56.

\section{References}

1. Rudskaja I. B., Fedorenko N.A. Analiz jeffektivnosti ispol'zovanija kadrovogo potenciala agrarnogo predprijatija [Analysis of the efficiency of using the personnel potential of an agricultural enterprise] // Sovremennye nauchnye issledovanija: problemy i perspektivy: Materialy IV Mezhdunarodnoj nauchno-prakticheskoj konferencii (14-15 nojabrja 2019 g., g. Zernograd) [Modern scientific research: problems and prospects: Materials of the IV International Scientific and Practical Conference (November 14-15, 2019, Zernograd)] / In M. N. Krylova (eds.). Moscow: Pero, 2019. — Pp. 108-113.

2. Savickaja G. V. Jekonomicheskij analiz: uchebnik. 14-e izd., pererab. i dop. [Economic analysis: textbook. 14th ed., reprint. and add.]. Moscow: INFRA-M, 2017. - 649 p. 
3. Semkin A. G. Mehanizm razvitija kadrovogo potenciala $\mathrm{V}$ sisteme APK [The mechanism of personnel potential development in the agro-industrial complex system] // Jekonomika sel'skogo hozjajstva Rossii [The economy of agriculture in Russia]. — 2017. - №4. Pp. 51-54.
4. Sharipov S., Harisov G. Ocenka jeffektivnosti ispol'zovanija proizvodstvennyh resursov APK [Evaluation of the efficiency of the use of production resources of the agro-industrial complex] // APK: jekonomika, upravlenie [Agro-industrial complex: economy, management]. — 2017. — №3. - Pp. 52-56.

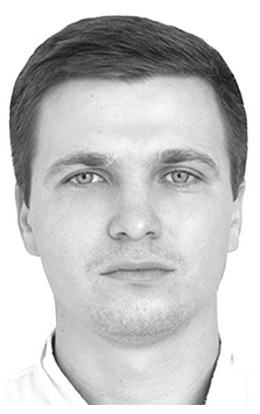

Федоренко Николай Александрович - магистрант Азово-Черноморского инженерного института, Донского государственного аграрного университета.

Fedorenko Nikolay Alexandrovich - Master's student, AzovBlack Sea Engineering Institute, Don State Agrarian University.

347740, г. Зерноград, ул. Ленина, 21

21 Lenina st., 347740, Zernograd, Russia

E-mail:kolia1509923@gmail.com

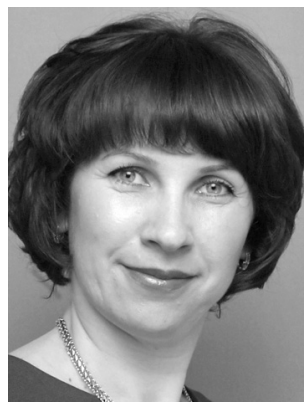

Рудская Ирина Борисовна - кандидат экономических наук, доцент Азово-Черноморского инженерного института, Донского государственного аграрного университета.

Rudskaya Irina Borisovna - Candidate of Economic Sciences, Associate Professor Azov-Black Sea Engineering Institute, Don State Agrarian University.

347740, г. Зерноград, ул. Ленина, 21

21 Lenina st., 347740, Zernograd, Russia

E-mail: i.rudskaya@mail.ru 